\title{
Exploring students' perceptions and opinions about an institutional hierarchy of healthcare professionals and its impact on their inter- professional learning outcomes
}

\author{
Raiharn Rabani iD, Michelle Key, Hana Morrissey iD, Patrick Ball iD \\ University of Wolverhampton, United Kingdom
}

\author{
Keywords \\ Inter-professional Learning \\ Institutional Hierarchy \\ Multidisciplinary \\ Stereotypes \\ Tribalism
}

\author{
Correspondence \\ Hana Morrissey \\ Reader in Clinical Pharmacy \\ University of Wolverhampton \\ Wulfruna Street \\ WV1 1LY \\ United Kingdom \\ hana.morrissey@wlv.ac.uk
}

\begin{abstract}
Context: Institutional hierarchy is a phenomenon associated with clinical tribalism. Inter-professional learning is thought to improve a healthcare team's collaboration and communication. Aim: The aim was to evaluate student understanding of institutional hierarchy and perceptions and opinions on their participation in interprofessional learning. Method: Using a questionnaire, this study gathered the opinions of fourth year pharmacy students who had completed two inter-professional learning sessions. Quantitative and qualitative analyses were conducted. Results: Students $(87.7 \%, n=50)$ were aware of the institutional hierarchy concept, listing the order as doctors, pharmacists, nurses then allied health. $61.4 \%(n=35)$ were willing to participate in inter-professional learning sessions. Students $(70.1 \%, n=40)$ agreed that inter-professional learning sessions have added benefit to patient-centred care, and to understanding different healthcare roles in depth $(82.5 \%, n=47)$ but failed in diminution of the hierarchical ideology. Conclusions: Inter-professional learning sessions did not change students' opinions about positioning of doctors as the top of the healthcare institutional hierarchy.
\end{abstract}

\section{Introduction}

All healthcare professionals from their area of specialisation, are highly valued in the management of patient's health, wellbeing and providing clinical advice. Inter-professional learning (IPL) or inter-professional education (IPE), is a learning approach used to improve undergraduate students' or practising healthcare professionals' understanding of each other's professional responsibilities, boundaries and ultimately improve their collaboration in the provision of patient healthcare (Buring et al., 2009). Inter-professional practice will optimise the use of the skills of the healthcare workforce (Buring et al., 2009). For this study, clinical tribalism was defined as a group of healthcare professionals with similar interests who have professional boundaries, not only defining their identity but also giving them perceived superior or inferior status over others in the multidisciplinary team (Brazil, 2014).

Hammick (1998), highlighted the initial definition of IPL as 'learning together to promote a collaborative practice'. The Centre for the Advancement of Inter-professional Education (CAIPE) introduced a broader definition, encompassing all clinical professionals and focusing on engagement to enforce collaborative practice. CAIPE defines IPL as, 'occasions when two or more professions learn with, from and about each other to improve collaboration and the quality of care' (CAIPE, 2002). The World Health Organisation (WHO) issued a report to establish IPL, acknowledging the importance of collaborative practice within a multidisciplinary education 
setting. This consisted of all healthcare professional students learning together in their early years of study to improve healthcare services thereby improving the effectiveness of teamwork in a clinical setting. A multidisciplinary education setting establishes skill sets that should enhance clinicians' ability to solve health related problems, particularly those susceptible to a teamworkbased approach (WHO, 1988).

Darlow and colleagues (2015) conducted a study assessing students' attitudes on IPL to identify changes postexposure. The study initiated an 11-hour IPL program of pre-registration students from mixed healthcare backgrounds (intervention) compared to their regular curriculum (control). The mean post-intervention attitude score was significantly higher in the intervention group. It was concluded that the IPL programme had 'improved attitudes towards inter-professional learning, self-reported confidence and self-reported ability to function within a multidisciplinary team.' This suggested that the IPL exposure had a significant and positive impact on undergraduate attitudes toward students from the other professions. The findings of this study were in line with the core inter-professional competencies stated by the WHO: teamwork, roles and responsibilities, communication, learning and critical reflection, developing working relationships with healthcare personnel and recognising the needs of the patient and ethical practice (WHO, 2010).

In a report commissioned by the United Kingdom Department of Health (DoH), the importance of IPL and collaborative practice for a patient's health and wellbeing was emphasised, identifying that the lack of organisation skills, failure to communicate, poor leadership, paternalism and 'club culture' can impact collaborative practice. The DoH report established that poor collaborative practice between members of the healthcare team can have 'catastrophic consequences' (Department of Health and Social Care, 2002).

IPL creates awareness of the prejudices in a work environment and exposes the ranking of positions. The process aims to reduce and eradicate work-related conflicts, enabling students and clinicians to collaborate through identifying each other's strengths and specialisms (Overton \& Lowry, 2013). Herath and colleagues (2017) conducted a systematic review on the effects of implementing IPL programmes in undergraduate and postgraduate courses. IPL programmes established at the undergraduate level, implemented the shared learning of skills, knowledge, values and practices. They highlighted that 'many countries, especially the academic institutions are benefiting from the implementation of IPE programmes' (Herath et al., 2017).
Mahler and colleagues (2018) studied student's opinions of IPL and deemed it to be a positive, innovative programme, emphasising the importance of greater collaboration with other healthcare professionals throughout undergraduate courses. IPL exposure resulted in 'students feeling at ease when approaching other healthcare professionals', during their time in practice (Mahler et al., 2018). Both studies promoted collaborative practice between all healthcare professionals and highlighted the need of future initiatives to pursue this approach for delivering better healthcare to patients.

'Institutional hierarchism' is defined as a structure within an organisation where one role is considered superior or more important compared to all other jobs rendering the remainder as being inferior or less important (NHS Scotland, 2013). Braithwaite and colleagues (2016) concluded that professional characteristics should be used as a basis for introducing more IPL and team-based collaborations. In contrast, another study concluded that specialist medical doctors working in an interdisciplinary environment, significantly influence the team's treatment recommendations (Abdulrahman et al., 2019). This further demonstrates the mis-match between training and real world practice.

\section{Study Purpose}

Research on pharmacy students' opinions and perceptions of institutional hierarchy and IPL, is limited. The current literature mainly examines nurses, doctors, and other allied health such as physiotherapy and occupational therapy, therefore, the additional findings will inform improvement of pharmacists' experience of taking part in IPL and how it can be designed to ensure inclusivity.

\section{Methods}

\section{Study design \& methods}

This was a questionnaire-based study. To enable access to all fourth year pharmacy students within a limited time, it was conducted at the end of a scheduled classroom session. There were 15 questions which were a mixture of open, closed and Likert style (Table I). The questionnaire used multiple choice questions with a single correct choice to avoid misinterpretations of questions and to facilitate data collation and analysis. Participants were also provided with a comment box with every question to enable them to enter free text (Mathers, Fox \& Hunn, 2009). Focus groups and interviews were considered unsuitable for this study due to time constraints (Smith, 2010). 


\section{Table I: List of study questions}

\begin{tabular}{|c|c|}
\hline & Study Questions: \\
\hline 1 & Do you believe an institutional hierarchy exists in healthcare? \\
\hline 2 & $\begin{array}{l}\text { The line below represents a healthcare institutional hierarchy ( } 5 \\
\text { points ladder). Please indicate where you feel pharmacists sit } \\
\text { within this hierarchy. }\end{array}$ \\
\hline 3 & $\begin{array}{l}\text { Which healthcare profession(s) do you think would be ranked } \\
\text { above a pharmacist in the hierarchy (if any). }\end{array}$ \\
\hline 4 & $\begin{array}{l}\text { Which healthcare profession(s) do you think would be ranked } \\
\text { below a pharmacist in the hierarchy (if any)? }\end{array}$ \\
\hline 5 & $\begin{array}{l}\text { Which healthcare professional do you think is the most important } \\
\text { when dealing with a patient? }\end{array}$ \\
\hline 6 & $\begin{array}{l}\text { Which healthcare professional do you think has the most } \\
\text { responsibility when dealing with a patient? }\end{array}$ \\
\hline 7 & $\begin{array}{l}\text { Interprofessional learning allows me to understand the roles of } \\
\text { other healthcare professionals (where } 1=\text { strongly disagree and } 5 \\
=\text { strongly agree). }\end{array}$ \\
\hline 8 & $\begin{array}{l}\text { Learning with other healthcare undergraduates is time consuming } \\
\text { (where } 1 \text { = strongly disagree and } 5=\text { strongly agree). }\end{array}$ \\
\hline 9 & $\begin{array}{l}\text { Learning with other healthcare undergraduates has no added } \\
\text { benefit to patient care (where } 1=\text { strongly disagree and } 5= \\
\text { strongly agree). }\end{array}$ \\
\hline 10 & $\begin{array}{l}\text { On a scale of } 1-5 \text { below, indicate how willing you are to } \\
\text { participate in both IPL experiences with other healthcare } \\
\text { professional students? ( } 1=\text { Highly unwilling and } 5=\text { Very willing). }\end{array}$ \\
\hline 11 & $\begin{array}{l}\text { Do you think Interprofessional Learning has equipped you with a } \\
\text { patient-centred approach for your future practice? }\end{array}$ \\
\hline 12 & $\begin{array}{l}\text { What have you learnt about other healthcare professional roles } \\
\text { from your IPL experiences? }\end{array}$ \\
\hline 13 & $\begin{array}{l}\text { Do you think anything limited the opportunity of learning about } \\
\text { other healthcare professional roles, from your IPL experiences? }\end{array}$ \\
\hline 14 & $\begin{array}{l}\text { Has your IPL experience changed your opinion of where different } \\
\text { healthcare professionals sit within an institutional hierarchy? }\end{array}$ \\
\hline 15 & $\begin{array}{l}\text { Reflecting back to your response from question } 2 \text {, would you have } \\
\text { placed a pharmacist differently on the hierarchy scale before } \\
\text { exposure to your IPL experiences? }\end{array}$ \\
\hline
\end{tabular}

\section{Data analysis}

Quantitative data were transcribed into percentages, charts and tables for further evaluation and qualitative data were processed through thematic analysis by manual identification of themes and agreement on the themes identified by the researcher and the co-researchers. Themes identified were short and precise, ensuring that statements were not presented as full opinions (Smith, 2010).

\section{Results}

Of the 74 students approached, 57 (77.0\%) students completed the survey. Participants were asked to answer each of the 15 questions and explain the reasoning behind their answers in a comment box at the end of each question

\section{Results related to Healthcare Institutional Hierarchy Participants Opinion on Healthcare Institutional Hierarchy} The introductory question established whether participants believed a healthcare professionals' institutional hierarchy exists, $82.4 \%(n=47)$ stated 'yes' (Table II).

\section{Place the Pharmacist on the Healthcare Institutional Hierarchy Scale}

A total $n=50(87.7 \%)$ answered this question. The mean ranking position for pharmacists was calculated as 2.64 (Figure I and Table II).

\section{Position of a pharmacist on a hierarchy scale}

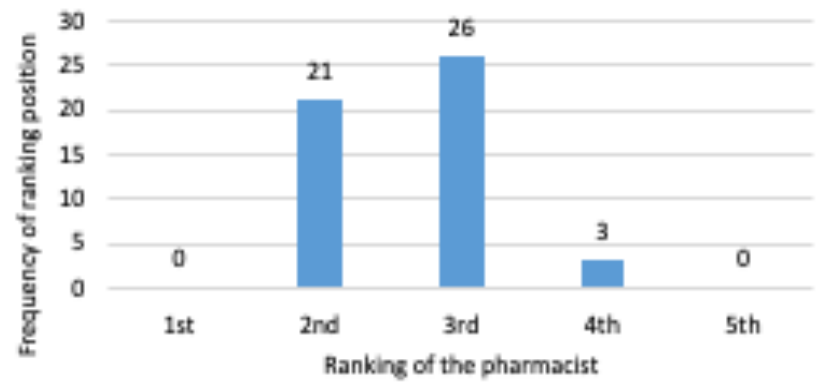

Figure I: Frequency of ranking position of a pharmacist according to 50 participants

\section{Order of Healthcare Institutional Hierarchy}

Participants were asked which professions they would place equal, above or below the pharmacist. Medical doctors and dentists were ranked higher than pharmacists by most participants (Figure II). 


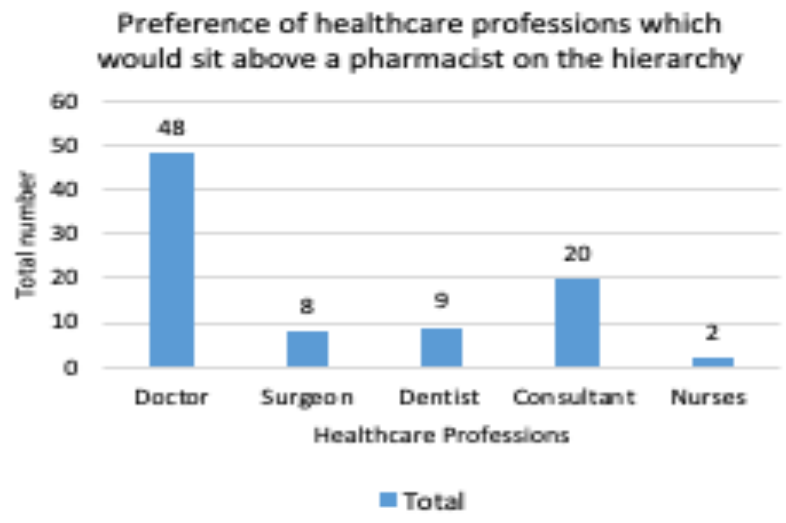

Figure II: Frequency of each named profession that would sit higher than a pharmacist

Nurses and allied health professionals were ranked below pharmacists by the majority of participants (Figure III). No profession was ranked as equal to pharmacists.

\section{Preference of healthcare professions which} would sit below a pharmacist on the hierarchy

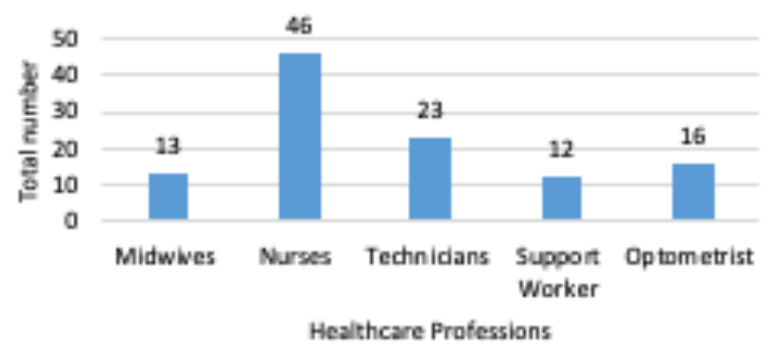

Figure III: Frequency of each named profession that would sit below a pharmacist

\section{Healthcare Profession Order of Importance}

Question 5 aimed to understand participants' opinions on which healthcare profession they think to be the most important. The theme 'all healthcare professions' was identified (Table II).

\section{Healthcare Profession Order of Responsibility}

Question 6 asked which profession had the most responsibility. Three responses were rejected as they failed to mention a single healthcare profession. All themes identified from question 5 were found in question 6 , sharing the same phrases and responses.

\section{Results related to Understanding and Participating in IPL Activities}

Participants were asked to comment on a set of statements about partaking in IPL activities and willingness to engage in the activities offered.

Question 7, 8 and 9 were Likert scale responses with their results presented in Figures IV-VI.

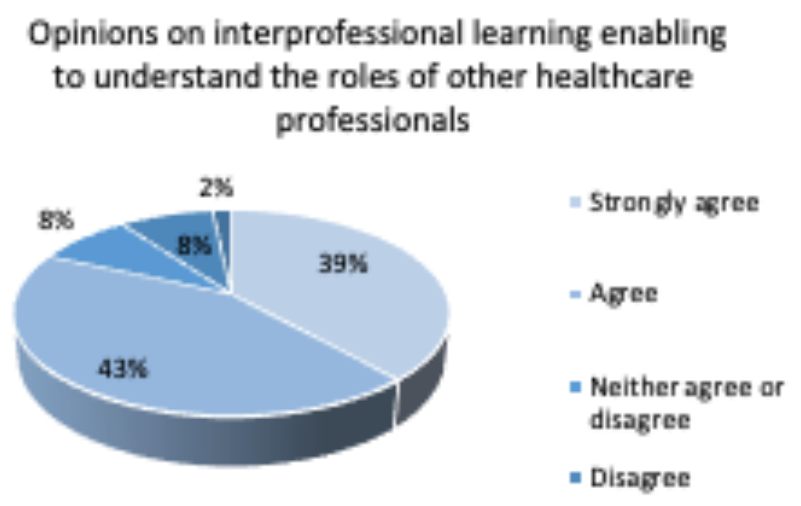

Figure IV: Participants opinion on understanding healthcare roles in IPL - Question 7

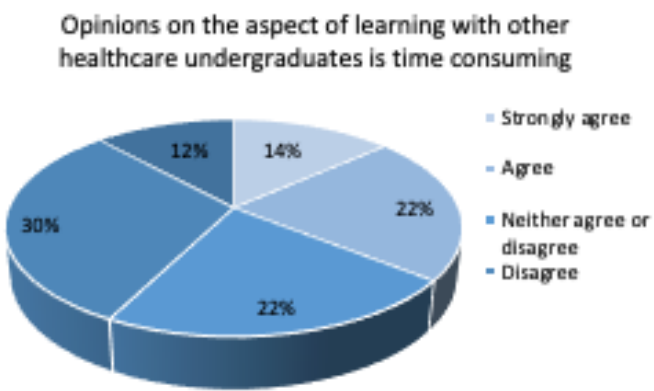

Figure V: Participants opinion on time and learning with other healthcare students - Question 8

Opinions on learning with other healthcare undergraduates having no added benefit to patient care

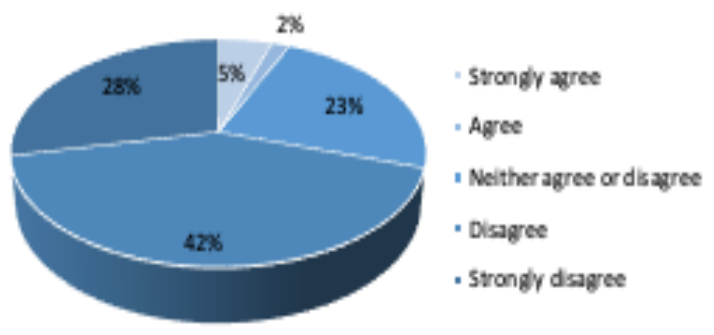

Figure VI: Participants opinion on learning with other healthcare students and its benefit to patient care 
Table II: Themes identified for study questions

\begin{tabular}{|c|c|c|}
\hline Theme & Descriptor & Participant (P) number and responses \\
\hline Responsibility & $\begin{array}{l}\text { Healthcare professionals have a range of } \\
\text { responsibilities and the level of responsibility varies. }\end{array}$ & $\begin{array}{l}\text { P6 - 'Responsibilities define the healthcare professional'. } \\
\text { P23 - 'Responsibility entails being liable, power and ranking'. } \\
\text { P42 - 'The more senior the role, the more responsibility'. }\end{array}$ \\
\hline Knowledge & $\begin{array}{l}\text { Healthcare professionals with more years of study } \\
\text { have higher level of knowledge and are ranked higher } \\
\text { on the hierarchy ladder. }\end{array}$ & $\begin{array}{l}\text { P17 - 'Doctors have more clinical knowledge'. } \\
\text { P54 - 'Pharmacists have more clinical knowledge than nurses'. }\end{array}$ \\
\hline Managers give structure & $\begin{array}{l}\text { Managers can be healthcare professionals or non- } \\
\text { healthcare professionals. }\end{array}$ & $\begin{array}{l}\text { P7 - 'A hierarchy determines final decisions'. } \\
\text { P2 - 'Everybody has to be liable and report back to a manager'. } \\
\text { P11 - 'Without structure there will be anarchy'. }\end{array}$ \\
\hline Career progression & $\begin{array}{l}\text { Restriction of code of practice limiting pharmacists' } \\
\text { progression as managers. }\end{array}$ & $\begin{array}{l}\text { P8 - 'Restriction of practice prevents development'. } \\
\text { P19 - 'Job role is capped'. } \\
\text { P32 - 'Unable to move ranks due to restriction of practice'. }\end{array}$ \\
\hline Salary difference & $\begin{array}{l}\text { Earned income could influence the existence of a } \\
\text { hierarchy. }\end{array}$ & $\begin{array}{l}\text { P9 - 'Earning determines a person's value'. } \\
\text { P18 - 'Salary defines professionals'. } \\
\text { P22 - 'Most skilled get paid more'. } \\
\text { P36 - 'Money talks and shows importance'. }\end{array}$ \\
\hline $\begin{array}{l}\text { Equality and } \\
\text { discrimination }\end{array}$ & $\begin{array}{l}\text { Those who stated 'yes' felt discrimination takes place, } \\
\text { whereas those who answered 'no' believe equality } \\
\text { exists. }\end{array}$ & $\begin{array}{l}\text { P4 - 'Everybody is equal as the focus is patient care'. } \\
\text { P5 - 'Club culture is a big thing'. } \\
\text { P13 - 'People only stick to who they know and reject others'. } \\
\text { P16 - 'Nobody discriminates'. } \\
\text { P35 - 'Patients are the main priority'. } \\
\text { P44 - 'Hatred amongst those who do not fit the role'. }\end{array}$ \\
\hline
\end{tabular}

Question 2

\begin{tabular}{|c|c|c|}
\hline Responsibility & $\begin{array}{l}\text { The higher the profession ranked the more } \\
\text { responsibility they have }\end{array}$ & $\begin{array}{l}\text { P5- 'Responsibility gives you more power'. } \\
\text { P18- 'Responsibility makes you relevant'. }\end{array}$ \\
\hline First line of contact & $\begin{array}{l}\text { Healthcare professionals who triage patients should } \\
\text { be ranked high due to their input on patient care }\end{array}$ & $\begin{array}{l}\text { P8- 'Pharmacists are first line of patient contact in a community setting'. } \\
\text { P14- 'Nurses are first line of contact in a hospital'. } \\
\text { P37- 'Doctors are involved in all stages of care'. }\end{array}$ \\
\hline Knowledge & Level of medical knowledge trigger higher ranking & $\begin{array}{l}\text { P3 - 'Pharmacists are specialist in drugs'. } \\
\text { P9- 'Doctors/medical specialists are specialist in diagnostics'. } \\
\text { P22- 'Doctors and pharmacists have more years of studying'. } \\
\text { P50- 'Pharmacists can only practice in minor aliments'. } \\
\text { P39- 'Nurses lack therapeutic drug knowledge'. }\end{array}$ \\
\hline
\end{tabular}

\begin{tabular}{|c|c|c|}
\hline \multicolumn{3}{|c|}{ Question 5} \\
\hline Decision Makers & $\begin{array}{l}\text { Clinicians who actively decide patient diagnosis and } \\
\text { treatment regimen are the most important. }\end{array}$ & $\begin{array}{l}\text { P15- 'Doctors are the decision makers'. } \\
\text { P4- 'Doctors overrule any opinion'. } \\
\text { P22- 'Doctors have the final say'. }\end{array}$ \\
\hline Prescribing Rights & $\begin{array}{l}\text { Clinician's with full prescribing rights should be } \\
\text { ranked higher than others }\end{array}$ & $\begin{array}{l}\text { P37 - 'Doctors can prescribe freely'. } \\
\text { P26- 'Prescribing freely requires more knowledge'. }\end{array}$ \\
\hline Level of Patient Contact & $\begin{array}{l}\text { Firstline Health professionals are ranked as more } \\
\text { important than others }\end{array}$ & $\begin{array}{l}\text { P9- 'Pharmacists are first line patient contact in a community setting'. } \\
\text { P13- 'Nurses are first line patient contact in a hospital setting'. } \\
\text { P20- 'Doctors are the first point of contact when diagnosing'. }\end{array}$ \\
\hline
\end{tabular}

\begin{tabular}{|c|c|c|}
\hline \multicolumn{3}{|c|}{ Question 10} \\
\hline $\begin{array}{l}\text { Insight into other } \\
\text { healthcare roles }\end{array}$ & $\begin{array}{l}\text { IPL experiences improved the level of understanding } \\
\text { about responsibilities and tasks of healthcare } \\
\text { professionals }\end{array}$ & $\begin{array}{l}\text { P5- 'Nurses have more responsibility'. } \\
\text { P11- 'Pharmacists are specialists in medication'. } \\
\text { P18- 'Doctors are diagnosticians'. }\end{array}$ \\
\hline $\begin{array}{l}\text { Development of mutual } \\
\text { respect }\end{array}$ & $\begin{array}{l}\text { IPL effect on student's perceptions of other } \\
\text { healthcare professionals. }\end{array}$ & $\begin{array}{l}\text { P2- 'Understand a nurse's job role better'. } \\
\text { P28- 'Doctors have more knowledge and responsibility'. } \\
\text { P35- 'Without nurses, patient care would be non-existent'. }\end{array}$ \\
\hline Learning gain & Opinion on the learning benefit of IPL. & $\begin{array}{l}\text { P3- 'Sessions not productive'. } \\
\text { P8- 'Did not learn'. } \\
\text { P14- 'Tailored to one healthcare role'. }\end{array}$ \\
\hline Time consuming & $\begin{array}{l}\text { Opinion on the length of the session effect on } \\
\text { learning outcomes. }\end{array}$ & $\begin{array}{l}\text { P16- 'Waste of time due to being long winded'. } \\
\text { P31- 'Unnecessarily long and dragged'. }\end{array}$ \\
\hline $\begin{array}{l}\text { Unwillingness to share } \\
\text { experiences }\end{array}$ & $\begin{array}{l}\text { Pharmacy students limited hands-on clinical skills, } \\
\text { negatively impacted the IPL experience, reducing } \\
\text { students to interest to engage. }\end{array}$ & $\begin{array}{l}\text { P54- 'Lack of engagement, like a normal lecture'. } \\
\text { P48- 'No discussion of healthcare roles'. } \\
\text { P37- 'Silent audience with no student interaction'. }\end{array}$ \\
\hline
\end{tabular}


Table II: Themes identified for study questions (continued)

\begin{tabular}{|c|c|c|}
\hline \multicolumn{3}{|c|}{ Question 11} \\
\hline $\begin{array}{l}\text { Insight into other } \\
\text { healthcare roles }\end{array}$ & $\begin{array}{l}\text { IPL experiences improved the level of } \\
\text { understanding about responsibilities and tasks of } \\
\text { healthcare professionals }\end{array}$ & $\begin{array}{l}\text { P5- 'Nurses have more responsibility'. } \\
\text { P11- 'Pharmacists are specialists in medication'. } \\
\text { P18- 'Doctors are diagnosticians'. }\end{array}$ \\
\hline $\begin{array}{l}\text { Development of } \\
\text { mutual respect }\end{array}$ & $\begin{array}{l}\text { IPL effect on student's perceptions of other } \\
\text { healthcare professionals. }\end{array}$ & $\begin{array}{l}\text { P2- 'Understand a nurse's job role better'. } \\
\text { P28- 'Doctors have more knowledge and responsibility'. } \\
\text { P35- 'Without nurses, patient care would be non-existent'. }\end{array}$ \\
\hline Learning gain & Opinion on the learning benefit of IPL. & $\begin{array}{l}\text { P3- 'Sessions not productive'. } \\
\text { P8- 'Did not learn'. } \\
\text { P14- 'Tailored to one healthcare role'. }\end{array}$ \\
\hline Time consuming & $\begin{array}{l}\text { Opinion on the length of the session effect on } \\
\text { learning outcomes. }\end{array}$ & $\begin{array}{l}\text { P16- 'Waste of time due to being long winded'. } \\
\text { P31- 'Unnecessarily long and dragged'. }\end{array}$ \\
\hline $\begin{array}{l}\text { Unwillingness to } \\
\text { share experiences }\end{array}$ & $\begin{array}{l}\text { Pharmacy students limited hands-on clinical } \\
\text { skills, negatively impacted the IPL experience, } \\
\text { reducing students to interest to engage. }\end{array}$ & $\begin{array}{l}\text { P54- 'Lack of engagement, like a normal lecture'. } \\
\text { P48- 'No discussion of healthcare roles'. } \\
\text { P37- 'Silent audience with no student interaction'. }\end{array}$ \\
\hline
\end{tabular}

Questions 12 and 13

\begin{tabular}{|c|c|c|}
\hline Career burden & $\begin{array}{l}\text { Understanding workload for each healthcare } \\
\text { professionals. }\end{array}$ & $\begin{array}{l}\text { P46 - 'Nurses have large workloads'. } \\
\text { P35- 'Doctors work several hours'. }\end{array}$ \\
\hline Knowledge & Lack of understanding of specialities. & $\begin{array}{l}\text { P32- 'Doctors don't specialise in medications'. } \\
\text { P28- 'Nurses are not diagnosticians'. }\end{array}$ \\
\hline $\begin{array}{l}\text { Multidisciplinary } \\
\text { team }\end{array}$ & $\begin{array}{l}\text { Importance of functional multidisciplinary team } \\
\text { in patient care and errors reduction. }\end{array}$ & $\begin{array}{l}\text { P19- 'Working together improves patient outcomes'. } \\
\text { P33- 'All healthcare professionals play a pivotal role'. } \\
\text { P44- 'Patients' life would be at an increased risk without all disciplines } \\
\text { actively involved'. }\end{array}$ \\
\hline Stereotypes & $\begin{array}{l}\text { Opinion on the impact of stereotyping of } \\
\text { healthcare professionals. }\end{array}$ & $\begin{array}{l}\text { P7- 'Pharmacists do not just push pills'. } \\
\text { P11- 'Doctors do not specialise in everything'. } \\
\text { P55- 'Nurses are not doctors' assistants'. }\end{array}$ \\
\hline Learning gain & $\begin{array}{l}\text { The value of knowledge gained from the IPL } \\
\text { sessions. }\end{array}$ & $\begin{array}{l}\text { P57- 'Did not allow me to learn anything'. } \\
\text { P13- 'Not informative, preventing knowledge to be obtained'. }\end{array}$ \\
\hline Limited structure & $\begin{array}{l}\text { IPL sessions structure and teaching to activities } \\
\text { ratio. }\end{array}$ & $\begin{array}{l}\text { P3- 'Not inclusive of other students'. } \\
\text { P4- 'A spokesperson dictated the lecture'. } \\
\text { P9- 'There was no group activities'. }\end{array}$ \\
\hline Frequency of IPL & Length and frequencies of the IPL sessions. & $\begin{array}{l}\text { P12- 'Far too short to learn anything'. } \\
\text { P16- 'Lack of sessions'. }\end{array}$ \\
\hline Poor inclusivity & $\begin{array}{l}\text { IPL sessions inclusion of all participating } \\
\text { healthcare roles not mainly focused on medical } \\
\text { and nursing students. }\end{array}$ & $\begin{array}{l}\text { P18- 'The sessions were catered to nurses'. } \\
\text { P20- 'Dominated by medical students'. } \\
\text { P22- 'Minimal interaction, only asked indirect questions to some } \\
\text { healthcare groups'. }\end{array}$ \\
\hline
\end{tabular}

\begin{tabular}{|c|c|c|}
\hline \multicolumn{3}{|c|}{ Questions 14 and 15} \\
\hline Responsibility & $\begin{array}{l}\text { IPL further students learning about each } \\
\text { healthcare role and what their job roles entail. }\end{array}$ & $\begin{array}{l}\text { P11- 'Predisposed opinion was biased until IPL'. } \\
\text { P17- 'IPL sessions altered my chain of understanding'. } \\
\text { P54- 'Roles of a pharmacist are understood better'. } \\
\text { P59- 'Nurses have more responsibility than expected'. }\end{array}$ \\
\hline $\begin{array}{l}\text { Collaborative } \\
\text { practice }\end{array}$ & $\begin{array}{l}\text { Opinion on how healthcare professionals } \\
\text { working together impact patient care. }\end{array}$ & $\begin{array}{l}\text { P50- 'Working together improves patient outcomes'. } \\
\text { P48- 'Professionals collaborating enhances patient care'. }\end{array}$ \\
\hline Opinion change & $\begin{array}{l}\text { IPL sessions impact on changing students' } \\
\text { opinion about other healthcare professionals. }\end{array}$ & $\begin{array}{l}\text { P15- 'Exposure was not sufficient to influence change'. } \\
\text { P31- 'Pharmacists are more clinically qualified, hence no change'. } \\
\text { P35- 'Frequency of IPL sessions limited learning outcomes, resulting in } \\
\text { no change'. } \\
\text { P37- 'Pharmacists have more responsibility so still hold the same } \\
\text { view'. } \\
\text { P45- 'Previous understanding is cemented'. }\end{array}$ \\
\hline $\begin{array}{l}\text { Experience } \\
\text { impacted decision }\end{array}$ & $\begin{array}{l}\text { Real world exposure and experiences compared } \\
\text { to the IPL sessions. }\end{array}$ & $\begin{array}{l}\text { P3- 'Working in the healthcare sector'. } \\
\text { P5- 'Working in a hospital setting created awareness'. } \\
\text { P7- 'University placements provided insight'. }\end{array}$ \\
\hline Knowledge & $\begin{array}{l}\text { The level of qualification and knowledge impact } \\
\text { ranking. }\end{array}$ & $\begin{array}{l}\text { P21- 'Pharmacists specialise in medication'. } \\
\text { P27- 'Pharmacists have more therapeutic understanding'. }\end{array}$ \\
\hline
\end{tabular}


Question 10 asked about their willingness to partake in IPL sessions with other healthcare professional students. The results showed that the majority were very willing to partake (Figure VII).

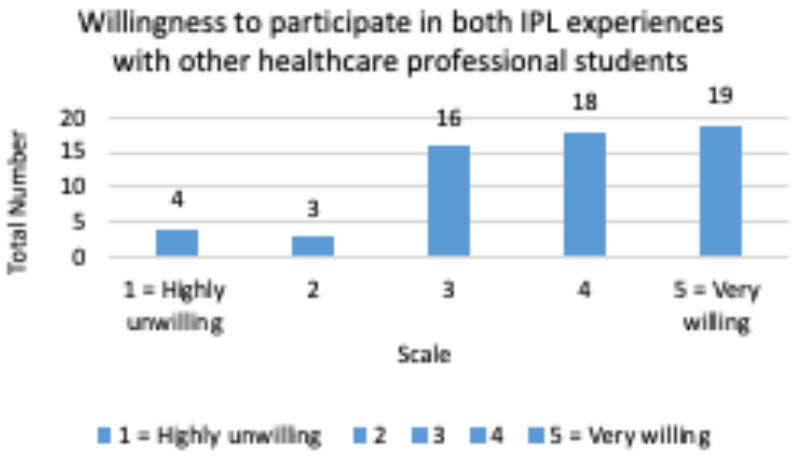

Figure VII: Participants opinion on their willingness to partake in IPL sessions

\section{Results related to opinions on participants IPL experiences}

The following set of questions asked participants' opinions on their experience of both IPL sessions during the Master of Pharmacy (M.Pharm.) course.

\section{IPL impact on students understanding of collaborative patient-centred approach}

Question 11 asked participants, whether they felt IPL equipped them with a collaborative patient-centred approach for the future practice, $61.9 \%$ responded yes.

\section{IPL Impact on Students Understanding of the Role of other Healthcare Professionals}

Students were asked about what they learned about other healthcare professionals' roles from both IPL sessions (questions 12 and 13). Themes identified are listed in Table II.

\section{IPL Impact on Students Understanding of Healthcare Professionals Institutional Hierarchy}

Had IPL influenced or changed their understanding on where healthcare professionals sit on the institutional hierarchy (Q14 and 15). The themes 'hierarchy still exists' and 'hierarchy provides structure' were disregarded as they did not specify whether the IPL experiences changed their views on where healthcare professionals sit within a hierarchy. Question 15 indicated that 82.4\% (n=47) participants selected they would have kept the pharmacist exactly the same on the scale versus $14.0 \%(n=8)$ said they would place the pharmacist higher on the scale and $3.5 \%$ $(n=2)$ said they would move the pharmacist lower.

\section{Discussion}

The majority of student respondents selected the option that hierarchy existed (82.5\%); popular themes were responsibility, salary and equality \& discrimination. Socioeconomic status influenced the existence of the institutional hierarchy. Greer and colleagues (2012) highlighted the conflicts within medical teams which resulted in tribalism. Such conflicts stem from status, reputation, opinions, level of authority, responsibility, uniforms, qualification, job title and income (Braithwaite, 2016). The implications of these jeopardise patient outcomes and limit collaborative practice (Abdulrahman, 2019). The study by Greer and colleagues (2012) only included doctors and nurses, but these factors can be applicable to pharmacy since they shape the multidisciplinary team.

Abdulrahman, (2019) found that despite having a team structure, hierarchies continue to influence decisionmaking, especially where senior members of the team were present. Sfantou and colleagues (2017) assessed leadership styles in a healthcare setting, concluding that managers are a critical component of any organisation. Increased productivity, strong work ethic and positive patient outcomes are dependent on the leadership style adopted. They noted that the leadership style of the manager was not directly related to the profession of the person undertaking the managerial role.

The theme of 'all professionals being equal' was prominent in those who believed a hierarchy did not exist (17.5\%). Carding (2019) reported professionals showed flexible attitudes towards patient safety when under pressure. He reported Professor Ted Baker of the Care Quality Commission stating:

'In so many of these [never] events we hear that a junior member knows what's happening but feels they can't challenge' as 'the culture in which they work does not support them taking the right action'

[Professor Baker said in Carding, 2019]

This suggests that healthcare professionals with less experience perceived a hierarchal gap, that those in senior 
positions will be more confident to speak up. A conflicted understanding between healthcare professionals could be a potential cause of unintentional hierarchism in Carding's findings, which could suggest the reason for the mixed responses to Q1 in this study.

A mean score of 2.64 was calculated as the pharmacists ranking within the hierarchy $(\mathrm{Q} 2$, Figure 1$)$ implying the role is perceived as having significance and value.

Responsibility, first line of contact and level of knowledge are themes that emerged out of the study results. A study analysing public opinions of pharmacists concluded the profession is highly valued, but that there was poor understanding of their scope of practice, perceiving it as not exceeding the supply of medication (Hindi, Schafheutle, \& Jacobs, 2017). Wilcock and Colleagues (2020) concluded that the involvement of clinically qualified pharmacists in patient care post-discharge, reduced readmission rates. Both studies are supportive of the themes implying pharmacists were ranked quite highly on the hierarchy. Although, both studies provide a patient's perspective of the role, it is interesting to observe the similarity between public and pharmacy students' opinions, since both perceived this role to be valuable and clinically qualified.

Students ranked doctors, medical specialists, surgeons, and dentists above a pharmacist, but perceived midwives, nurses, technicians, support workers and optometrists to be below a pharmacist; $42.2 \%$, however, indicated nurses were believed the most responsible (Q4, Figure III).

Overall, doctors were ranked higher, followed by nurses being lower (Figure II and III). A study assessing physicians and nurses' attitudes towards each other, highlighted the traditional understanding of professional roles as a hierarchal status, concluding that doctors were the dominant profession with nurses perceived as being doctor's assistants (Vazirani et al., 2005). This study did not incorporate all healthcare professions, but demonstrated doctors ranked highly and nurses were positioned lower, resembling the finding of the current study.

On the aspect of importance and responsibility ( $Q 5$ and Q6), the responses emphasised doctors, and specifically medical specialists, were perceived as having extensive responsibility. The theme 'level of patient contact' identified, could be referring to 'accessibility to patient care' e.g. pharmacists being perceived to be the first point of contact in a community setting, or time spent on patient care e.g. nurses spend more time with patients. The similar theme in Q2, 'first line of patient contact' was a consideration in ranking the professions.
Nurses were ranked below a pharmacist but were perceived as the most responsible. This implied knowledge, patient engagement and exposure were the major considerations compared to responsibility, respectively.

It was evident $(82.5 \%$ agreed) that IPL enables understanding of other healthcare professions' roles and responsibilities. Supporting research on IPL for medical and nursing students by Homeyer and colleagues (2018), illustrated how this reinforced co-operation, effective communication and understanding of roles, produces improvements in patient- centred care.

Participants opinions about the length of time they spent in the IPL sessions (Q8) Illustrated in Figure V, with $36.8 \%$ seeing the sessions as time consuming (Figure $\mathrm{V}$ ).

Most respondents disagreed (70.1\%) with the statement that IPL provided no added benefit to patient care (Q9, Figure VI). A supportive study looked at the benefits of IPL and teamwork in primary care, outlining improved education, personal development, patient care and job satisfaction (Carney et al., 2019). Their findings support the opinions held by most participants. Only $61.4 \%$ of students indicated willingness to participate in future IPL sessions suggesting the current model employed could be improved. The positive themes presented were an insight into roles and mutual respect. The negative themes were identified as time consuming, perceived low learning gain and unwillingness to share experiences. These themes concur with Carney's (2019) findings on the effectiveness of IPL. Further research would be required for an in-depth analysis.

Of participants, $61.4 \%$ agreed IPL equipped them for a patient-centred approach for future practice (Q11). Positive themes were the understanding of roles, collaborative practice and effective communication. These findings resonate with those of Darlow and colleagues (2015), emphasising that IPL provides in-depth knowledge about differing roles, self-reported ability to communicate openly and improved personal development skills, facilitating a better patient-centred approach. Poor inclusivity and frequency of sessions were negative themes which require further examination; however, the overall result shows the overall experience was beneficial overall, serving the purpose of IPL.

Participants' understanding of healthcare roles (Q12) associated the theme 'career burden' to doctors and nurses, implying their commitment to long working hours and a larger workload compared to others was a significant factor. A second theme, stereotypes, illustrated beliefs on previously held beliefs that were overcome from 
attending the IPL sessions. Vazirani and colleagues (2005) elaborated on traditional misconceptions and how IPL eradicates stereotypes, the most common being that nurses are subordinate to doctors.

The final theme of knowledge implied scope of practice being restricted to each specialism, highlighting capabilities and level of practice were specific to particular roles. The theme Importance of a multidisciplinary team agrees with the findings of Homeyer and colleagues (2018), which emphasised co-operation and teamwork with all healthcare roles improving patient outcomes.

Negative themes concerning limitations in learning were identified (Q13): 'limited structure', 'the frequency of IPL and poor inclusivity', which outlined why some participants may not have fully benefited from the sessions. This could suggest, students' willingness to take part could have been influenced by these limitations. This also requires further study. Conversely, a single theme: 'no limitations', was supportive of the IPL sessions, implying some felt the experience was beneficial.

The majority (67.3\%) did not change their opinion on IPL affecting perceptions of where professionals sit in a hierarchy. The positive themes: 'responsibility and collaborative practice' were supported by Mahler and colleagues (2018), who concluded participants recognised the benefits of IPL once they understand the responsibilities of each healthcare role and the importance of a collaborative practice.

Finally, the views on placing the pharmacist differently on the hierarchical scale before exposure to IPL identified an unchanged view in $82.4 \%$. Key themes: 'experience', 'responsibility and knowledge' all contributed to ranking the pharmacist in the same position. However, the theme unchanged opinion was unaffected from IPL exposure. Supportive literature by Hindi, Schafheutle and Jacobs (2017), and Wilcock and colleagues (2020), suggests why pharmacists were ranked highly, as they are deemed highly valuable and clinically qualified.

\section{Limitations}

The three limitations for this study are: that it was conducted at single centre, that only pharmacy students' opinions were collected and only a single year cohort were questioned. This limits generalisability, but the results of this study were supported by other studies and contribute to the wider literature in this area.

\section{Conclusions}

This study This study confirmed that many believed a hierarchy exists and demonstrated some understanding of this concept, but undertaking IPL currently used did not alter the hierarchy.

There were negative views on the hierarchy, but IPL overall was well attended based on willingness of undergraduate students to participate and the perceived future benefit to more patient-centred collaborative practice. IPL sessions did not change students' opinions about the positioning of doctors as the top of the healthcare institutional hierarchy.

\section{References}

Abdulrahman, M., Alsabbagh, A., Kuntze, T., Lauer, B.. \& Ohlow, M.A. (2019) Impact of Hierarchy on Multidisciplinary Heart-Team Recommendations in Patients with Isolated Multivessel Coronary Artery Disease (online). Journal of clinical medicine, 8(9), 1490. https://doi.org/10.3390/jcm8091490

Braithwaite, J., Clay-Williams, R., Vecellio, E., Marks, D., Hooper, T., Westbrook, M., Westbrook, J., Blakely, B., \& Ludlow, K. (2016) The basis of clinical tribalism, hierarchy and stereotyping: a laboratorycontrolled teamwork experiment (online). BMJ Open, 6(7), https:// doi.org/10.1136/bmjopen-2016-012467

Brazil, V. (2014) The Tribal Nature of Medicine (online). Available from: https://emergencypedia.com/2014/04/06/tribalism-in-medicine/

Buring, S.M., Bhushan, A., Broeseker, A., Conway, S., DuncanHewitt, W., Hansen, L., \& Westberg, S. (2009) Interprofessional Education: Definitions, Student Competencies, and Guidelines for Implementation (online). American Journal Of Pharmaceutical Education, 73(4), 59. https://doi.org/10.5688/aj730459

CAIPE (The Centre for the Advancement of Interprofessional Education). (2002) What is CAIPE?. Available at: https:// www.caipe.org/about-us

Carding, N. (2019) NHS hierarchies put patients at risk says CQC chief (online). Health Services Journal. Available at: https:// www.hsj.co.uk/patient-safety/nhs-hierarchies-put-patients-at-risksays-cqc-chief/7024867.article

Carney, P.A., Thayer, E.K., Palmer, R., Galper, A.B., Zierler, B., \& Eiff, P. (2019) The benefits of interprofessional learning and teamwork in primary care ambulatory training settings (online). Journal of Interprofessional Education \& Practice, 15, 119-126. https:// doi.org/10.1016/j.xjep.2019.03.011

Darlow, B., Coleman, K., McKinlay, E., Donovan, S., Beckingsale, L., Gray, B., Neser, H., Perry, M., Stanley, J., \& Pullon, S. (2015). The positive impact of interprofessional education: a controlled trial to evaluate a programme for health professional students. $B M C$ Medical Education, 15, 98. https://doi.org/10.1186/ $\underline{\text { s12909-015-0385-3 }}$ 
Department of Health and Social Care. (2002). The Department of Health's response to the report of the Public Inquiry into children's heart surgery at the Bristol Royal Infirmary (online). Available at: https://www.gov.uk/government/publications/the-departmentof-healths-response-to-the-report-of-the-public-inquiry-intochildrens-heart-surgery-at-the-bristol-royal-infirmary

Greer, L.L., Saygi, O., Aaldering, H., \& de Dreu, C.K.W. (2012) Conflict in medical teams: opportunity or danger? (online). Medical Education, 46(10), 935-942. https://doi.org/10.1111/ j.1365-2923.2012.04321.x

Hammick, M. (1998) Interprofessional Education: Concept, Theory and Application (online). Journal of Interprofessional Care, 12(3), 323-332. https://doi.org/10.3109/13561829809014123

Herath, C., Zhou, Y., Gan, Y., Nakandawire, N., Gong, Y., \& Lu, Z. (2017) A comparative study of interprofessional education in global health care (online). Medicine (Baltimore), 96(38), https:// doi.org/10.1097/MD.0000000000007336

Hindi, A.M.K., Schafheutle, E.I., \& Jacobs, S. (2017). Patient and public perspectives of community pharmacies in the United Kingdom: A systematic review (online). Health Expectations, 21(2), 409-428. https://doi.org/10.1111/hex.12639

Homeyer, S., Hoffmann, W., Hingst, P., Oppermann, R.F., \& DreierWolfgramm, A. (2018) Effects of interprofessional education for medical and nursing students: enablers, barriers and expectations for optimizing future interprofessional collaboration - a qualitative study. BMC Nursing, 17, 13. https://doi.org/10.1186/ $\underline{\text { s12912-018-0279-x }}$

Laming, W.H. (2003) The Victoria Climbie Inquiry: report of an inquiry by Lord Laming (online). Available at: https://www.gov.uk/ government/publications/the-victoria-climbie-inquiry-report-ofan-inquiry-by-lord-laming

Mahler, C., Schwarzbeck, V., Mink, J., \& Goetz, K. (2018) Students' perception of interprofessional education in the bachelor programme 'Interprofessional Health Care' in Heidelberg, Germany: an exploratory case study. BMC Medical Education 18, 19. https://doi.org/10.1186/s12909-018-1124-3

Mathers, N., Fox N., \& Hunn A. (2007). Surveys and Questionnaires. The NIHR RDS for the East Midlands / Yorkshire \& the Humber (online). Available at: https://www.rds-yh.nihr.ac.uk/ wp-content/uploads/2013/05/12 Surveys and Questionn aires Revision 2009.pdf

National Health Service Scotland. (2013). Patient Safety Education Scenario (online). Available at: https://www.nes.scot.nhs.uk/ media/1705869/ipl patient safety web.pdf

Overton, A.R., \& Lowry, A.C. (2013). Conflict Management: Difficult Conversations with Difficult People (online). Clinics in Colon and Rectal Surgery, 26(4), 259-264. https://doi.org/ $\underline{10.1055 / \mathrm{s}-0033-1356728}$
Sfantou, D.F., Laliotis, A., Patelarou, A.E., Sifaki- Pistolla, D., Matalliotakis, M., \& Patelarou, E. (2017). Importance of Leadership Style towards Quality of Care Measures in Healthcare Settings: A Systematic Review. Healthcare (Basel, Switzerland), 5(4), 73. https://doi.org/10.3390/healthcare5040073

Smith, F. (2010) Conducting Your Pharmacy Practice Research Project. Second edition ed. London, UK: Pharmaceutical Press, pp. 75-197

Vazirani, S., Hays, R., Shapiro, M., \& Cowan, M. (2005). Effect of a multidisciplinary intervention on communication and collaboration among physicians and nurses (online). American Journal of Critical Care, 14(1), 71-77. https://doi.org/10.4037/ajcc2005.14.1.71

Wilcock, M., Sibley, A., Blackwell, R., Kluettgens, B., Robens, S., \& Bastian, L. (2020) Involving community pharmacists in transfer of care from hospital: Indications of reduced 30-day hospital readmission rates for patients in Cornwall. International Journal of Pharmacy Practice. https://doi.org/10.1111/ijpp.12603

World Health Organization (1988) Learning Together to Work Together for Health. Available at: https://apps.who.int/iris/ bitstream/handle/10665/37411/WHO TRS 769.pdf; jsessionid=01D0F74D19FCF5CF850CD3497BDCD3CC? sequence $=1$

World Health Organization. (2010). Framework for Action on Interprofessional Education \& Collaborative Practice (online). Available at: https://apps.who.int/iris/bitstream/handle/ 10665/70185/WHO HRH HPN 10.3 eng.pdf;jsessionid= 7676F8DE0EBFD68ED3C841172ECBFE62? sequence=1 